\title{
Does Community Engagement Lead to Effective Decision Making? An Evidence from Karnataka Watershed Development Agency, India
}

\section{G. Ananda Vadivelu}

Indian Institute of Forest Management, Nehru Nagar, Bhopal - 462 003, India

Email: gananda@iifm.ac.in, vadivelu26@rediffmail.com

How to cite this paper: Vadivelu, G.A. (2018). Does Community Engagement Lead to Effective Decision Making? An Evidence from Karnataka Watershed Development Agency, India. Grassroots Journal of Natural Resources, 1(2): 35-47. Doi: https://doi.org/10.33002/nr2581.6853.01024

Received: 15 October 2018

Reviewed: 22 December 2018

Provisionally Accepted: 23 December 2018

Revised: 24 December 2018

Finally Accepted: 24 December 2018

Published: 31 December 2018

Copyright $(2018$ by author(s) and

The Grassroots Institute.

This work is licensed under the Creative Commons Attribution International License (CC BY 4.0).

http://creativecommons.org/licenses/by/4.0/

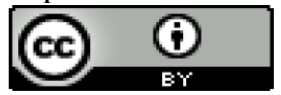

Open Access

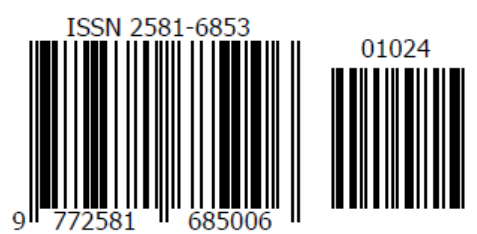

\begin{abstract}
Participation has both an intrinsic and instrumental value, and livelihood enhancement is achieved by fostering the effective engagement with the target community. As an implementation agency for the Karnataka Watershed Development Agency in Chitradurga district, MYRADA followed the building block approach. This meant that there was enough engagement with the village community in organising affinity groups involved in credit activities, before wider village level institutions were crafted. In this article, it is examined whether such an engagement lead to effective decision-making with respect to the soil and water conservation treatment undertaken on the farmers' land. Contrary to the theoretical proposition of the Olson (1965) that smaller the size better is the provisioning of the collective good, present field study found that provisioning by such groups could also lead to a bad outcome.
\end{abstract}

\section{Keywords}

Participation; Soil and Water Conservation; Watershed Development 


\section{Introduction}

UK's Department for International Development (DFID) supported the Government of Karnataka (GoK) in starting the Karnataka Watershed Development Agency (KAWAD) project. The KAWAD project envisaged creation of social capital by the initiation of various CommunityBased Organisations (CBOs) to ensure participation of the local community. The CBOs that were formed were supposed to facilitate cohesive mechanisms of working together to achieve a common goal. In this paper, we examine the participation of farmers in KAWAD project with respect to a crucial variable "decision making on the soil and water conservation treatment undertaken in the farmers' land.

The crafting of institutions and rules to allocate benefits and costs of collective action in a given community is an attempt to create social capital (Ostrom, 1990). According to Ostrom, "social capital is the shared knowledge, understandings, norms, rules and expectations about patterns of interactions that group of individuals bring to a recurrent activity" (Ostrom, 1990, p.176). An important norm that is supposed to be developed is that one should forgo self-interest, and act in the interest of the collectivity (Coleman, 1988, p.104). Therefore, social capital is considered as the institutional solution to solve the free-rider problem and make collective action possible.

The participation has both an intrinsic and instrumental value. The intrinsic value lies in the fact wherein community may simply value the simple fact of being listened to. The participation can also be used as an instrument to achieve objectives like enhancing livelihood opportunities, reducing socio-economic inequality, and so on (Mansuri and Rao, 2013, pp.89-91). The participation, however, is not a simple linear process, but dynamic in nature. Cornwall rightly states:

"Participation as praxis is, after all, rarely a seamless process; rather, it constitutes a terrain of contestation, in which relations of power between different actors, each with their own 'projects', shape and reshape the boundaries of action" (Cornwall, 2008, p.276).

Further, participation can be organic or induced. Organic participation emerges, when local groups act independently of government, while induced participation is promoted by the policy action of the State and implemented through bureaucracies, donors or NGOs. The main challenges of induced participation are that the effectiveness of community-driven interventions at the local level is conditioned by local capacity. Second, it is important whether the local organization is financially dependent on external donors or is able to generate revenue by itself. Third, in the evaluation of a project, one should consider discrepancies between short-term and long-term success. While the donor's institutional structures and incentives are tailored towards short timelines, community change is often time consuming and unpredictable (Mansuri and Rao, 2013). A study on Joint Forest Management (JFM) investigated whether the involvement of external agent leads to durable collective action at the local level (Barnes and Van Laerhoven, 2013). It examined the JFM intervention implemented with the support of an NGO in Maharashtra, India. The results showed that there was a weak correlation between NGO's involvement and expected sustainability of local collective action. The study found that such interventions did not appear to lead directly to durable forms of collective action in groups where it did not previously exist (Barnes and Van Laerhoven, 2013).

Scientific literature indicates that two key parameters that determine behaviour in groups are the size of the group and the homogeneity/heterogeneity of the community. Olson (1965) 
distinguishes small groups from large ones with the following characteristics. Small groups can provide themselves with collective good without having to rely on coercion or positive inducements, as all members or at least one of them would be ready to bear the entire costs rather than forego the collective good. While in larger groups, there would be an attempt by the members to free ride on others' contribution and the cumulative process would lead to underprovisioning.

The under-provisioning of collective good in smaller groups is also based on considerations such as the nature of benefit available from such a good, uncertainties involved, issues related to the property rights of the 'new' resources and access rights. In contrast, in large groups "no single individual's contribution makes a perceptible difference to the group as a whole; or the burden or benefit of any single member of the group, it is certain that a collective good will not be provided unless there is coercion or some outside inducements that will lead the members of the large group to act in their common interest" (Olson, 1965, p.44). Hence, "larger the group, smaller is the benefit each individual receives and there is less adequate reward for group-oriented action and farther the group falls short of getting an optimal supply of the collective good" (Olson, 1965, p.44).

The rationale for smaller groups is based on the consideration that 'highly personalised relationships' occurring in such groups and individuals would have 'a strong incentive to consider the more indirect and long-term consequences of their choices instead of paying attention to immediate benefits and costs' (Baland and Platteau, 1996, pp.298-299). However, it is also recognised that small groups also provide opportunities for personal antagonism and rivalries, which might be lesser in 'large' groups. Ostrom (1990) suggests that size is not a strong design principle for common property regimes and instead argues that effective leadership can help groups overcome problems of large group membership. The 21 case studies of Singh and Ballabh (1994) of local cooperatives related to fisheries, forests and water resources in India suggest that size and composition of membership did not have a significant effect on cooperative performance (cited in Keohae and Ostrom, 1995). Basing on an intensive study of two villages in Mali, Vedeld (2000) also supports the argument that 'leadership matters more than the size'.

The classic argument of how heterogeneity facilitates the provisioning of the collective good is Olson's contribution wherein he argues that "a group which has members of highly unequal degrees of interest in a collective good, and which wants a collective good that is (at some level of provision) extremely valuable in relation to its cost, will be more apt to provide itself with a collective good than other groups with the same number of members" (Olson, 1965, p.45). The larger size of members tends to share a larger burden of provision, as they receive larger benefits from the collective good. On the contrary, the "smaller size of members, by definition, receives a smaller fraction of the benefit of any amount from the collective good than a larger size of members, and, therefore, they have less incentives to provide additional amounts of collective good" (Olson, 1965, p.35). Therefore, it is concluded that heterogeneity does facilitate collective action processes.

An empirical support for the Olsonian proposition is provided by study of Wade (1988) that found that the inter-household differences in landholding and wealth did contribute to the members (particularly the larger members) taking an active interest in providing the collective 
good $^{1}$ (Wade, 1988). Additional important factor is the capacity of the villagers to work together. In the Indo-German Watershed Development Programme (IGWDP), the screening criteria for villages ensured that the village selected has in the past worked collectively (Farrington and Lobo, 1997). In terms of the screening criteria for villages, those with wide disparities in landholding were selected. The success of the IGWDP intervention was heterogeneity in landholding. This means that there was huge variation in land ownership.

Another study that provides contrary evidence to the Olsonian proposition is the contribution by D'Silva and Pai (2003), who examined the causative factors for relative success and comparative failure along three villages in Adilabad district of Andhra Pradesh. In the homogenous (tribal) village, there were better processes through crafting of SHGs institutions in the village that played an active role in ensuring better outcomes (increase in crop productivity, groundwater recharge, increase in income from fisheries), while the non-tribal villages had poor processes as they suffered from disunity, competition and factionalism. Aggarwal (2000) demonstrates how homogeneity is a significant factor in determining collective action processes. The study involved an examination of the functioning of the management of group wells in two villages in Andhra Pradesh. The activities involved allocation of water where there were no conflicts (except in three cases wherein it included members of different castes); maintenance activities were carried out more in the case of groups wherein there were relatives.

The empirical review indicates that, in some cases, heterogeneity facilitates the collective action process, whereas, in some cases, it does not. For us, the more important factor relates to as to how heterogeneous village communities are organised into affinity groups. MYRADA ${ }^{2}$ has followed the building block approach wherein enough time was spent in organising affinity groups involved in credit activities, and, based on the capabilities, built up wider village level institutions either related to forest management or watershed management (Fernandez, 1994). The MYRADA approach of Self-Help Group (SHG) based community-based organisations (CBOs) shows as to how, in heterogeneous village communities, the initial build-up of homogenous affinity groups could facilitate wider village-based community organisations at a later stage. The KAWAD project has adopted this as an approach to tackle the problems of heterogeneity.

Based on the earlier theoretical discussion, we intend to provide answer to the following question: Whether social capital formation in heterogeneous communities by creation of small groups is sufficient to ensure the provisioning of the collective good? This we believe would be a useful contribution and will stimulate further discourse in this arena.

\section{Study Area and Methodology}

Chitradurga district is a semi-arid ${ }^{3}$ and backward district. The district lies in the Krishna River basin having two major rivers: Vedavathi and Tunghabhadra. The mean annual rainfall for the

\footnotetext{
${ }^{1}$ Supporting the Olsonian argument of larger members have greater incentive to facilitate the provision of the collective good.

${ }^{2}$ MYRADA is a national NGO based in Bangalore, India. http://www.myrada.org/

${ }^{3}$ The mean annual rainfall in the district was $565 \mathrm{~mm}$ during the 1901 to 1990 period. In the study area of Molkalmuru taluk period, since the intervention of both DPAP (II phase projects) and KAWAD, it has ranged from a high of $876.70 \mathrm{~mm}$ in 1999 in comparison to a low of $441.20 \mathrm{~mm}$ in 2002 (for the years 2000 and 2001, it was $591.80 \mathrm{~mm}$ and $562.70 \mathrm{~mm}$, respectively). 
1901 to 1990 period was $565 \mathrm{~mm}$. Chitradurga sistrict falls under the Central Dry Agro Climatic Zone, which comprises 17 taluks from Chitradurga as well as Tumkur districts. The KAWAD project was implemented under the leadership of MYRADA, an NGO that has demonstrated its capabilities in initiating participatory approaches, while drought prone area programme (DPAP) was implemented by the Watershed Department of the Government of Karnataka. Molkalmuru taluk in Chitradurga district was selected for the study because both DPAP and KAWAD were implemented in this taluk as part of a wider study.

The micro watershed was delineated into the upper and lower reach. Further, farm households were classified into small, medium and large, based on size of landholding. The strata arrived at were as follows: upper small, upper medium, upper large, lower small, lower medium and lower large ${ }^{4}$. From each stratum, 25 per cent of the households were selected using the lottery method. Data was collected from 175 households. The data was collected from five villages and the profile of the villages is provided in Table 1 below.

Table 1: Profile of KAWAD study villages

\begin{tabular}{|c|l|l|l|l|l|l|l|}
\hline $\begin{array}{l}\text { Sl. } \\
\text { No. }\end{array}$ & Name of the village & $\begin{array}{l}\text { Number } \\
\text { of house- } \\
\text { holds }\end{array}$ & $\begin{array}{l}\text { Total } \\
\text { Area } \\
(\mathrm{ha})\end{array}$ & $\begin{array}{l}\text { Dry land } \\
(\mathrm{ha})\end{array}$ & $\begin{array}{l}\text { Irrigated } \\
(\mathrm{ha})\end{array}$ & $\begin{array}{l}\text { Cultivable } \\
\text { wasteland } \\
\text { (ha) })\end{array}$ & $\begin{array}{l}\text { Area not } \\
\text { available for } \\
\text { cultivation } \\
\text { (ha) }\end{array}$ \\
\hline 1 & Marlahalli & 204 & 666.35 & 386.75 & 43.22 & 386.75 & 27.54 \\
\hline 2 & Tumkurlahalli & 433 & $1166.45^{5}$ & 630.31 & 63.6 & 165.94 & 32.38 \\
\hline 3 & Rayapura & 382 & 436.95 & 290.93 & 91.54 & 81.45 & 18.80 \\
\hline 4 & Bommalinganahalli & 211 & 411.01 & 112.80 & 134.82 & 83.85 & 27.85 \\
\hline 5 & $\begin{array}{l}\text { Devarahatti (or } \\
\text { Chikkumthi) }\end{array}$ & 180 & 720.56 & 405.48 & 19.92 & 122.23 & 42.11 \\
\hline
\end{tabular}

Source: GoI, 1991 and MWSDC records.

\section{Findings}

In the demand driven approach, farmers request for a particular type of treatment making upfront contributions with final decision is taken by Micro Watershed Development Committee (MWSDC) and NGO staff. Based on this, a consolidated plan is prepared and sent to KAWAD secretariat. In the KAWAD mode, it was envisaged that at least five SHGs would be constituted before the formation of the MWSDC. The SHG members were also supposed to represent as the members of the MWSDC. This was to ensure better processes of planning and implementation of the watershed programme.

In the five study villages, 77 percent of the farmers had at least one of their household members in an $\mathrm{SHG}^{6}$ (Table 2). Among 26 percent of the farmers, who had two of their household members in SHGs, the highest proportion was from the upper large strata farmers (48\%). Such widespread participation by the farmers in the upper large strata was due to their ability to

\footnotetext{
${ }^{4} \mathrm{~A}$ farm household is called as small if landholding is less than 5 acres, medium if it owns between 5 to 10 acres and large if it owned more than 10 acres. One acre of irrigated land is considered to be equivalent to 2 acres of dry land.

5 The MWSDC selected for the study belongs to the uninhabited village of Adavimallapura, which has a total area of 361.55 ha.

${ }^{6}$ Village-wise evidence shows that this proportion was the highest in Bommalinganahalli (85\%), followed by

Devarahatti (84\%), Rayapura (81\%), Tumkurlahalli (79\%) and Marlahalli (72\%).
}

G. Ananda Vadivelu 
contribute periodic savings, and their entrepreneurial spirit in having more household members in KAWAD-initiated SHGs. This was an attempt to ensure that maximum gains from the mostly soft loans given under the project could be captured ${ }^{7}$.

Table 2: Membership in KAWAD initiated SHGs

\begin{tabular}{|l|l|l|l|l|l|l|}
\hline \multirow{2}{*}{ Stratum } & \multicolumn{6}{l|}{ Number of household members in SHGs (\%) } \\
\cline { 2 - 7 } & None & One & Two & Three & Four & Total \\
\hline Upper small & 19 & 53 & 28 & 0 & 0 & $100(26)$ \\
\hline Upper medium & 21 & 66 & 13 & 0 & 0 & $100(29)$ \\
\hline Upper large & 13 & 30 & 48 & 5 & 4 & $100(23)$ \\
\hline Lower small & 7 & 53 & 28 & 12 & 0 & $100(27)$ \\
\hline Lower medium & 26 & 47 & 21 & 6 & 0 & $100(34)$ \\
\hline Lower large & 28 & 42 & 22 & 8 & 0 & $100(36)$ \\
\hline Total & $23(40)$ & $38(66)$ & $26(45)$ & $7(12)$ & $7(12)$ & $100(175)$ \\
\hline
\end{tabular}

Note: Figures in parentheses are actual numbers

The village-wise evidence shows that the proportion of households having at least one of the household members in the SHG was the highest in Bommalinganahalli followed by Devarahatti, Rayapura, Tumkurlahalli and Marlahalli (Table 3). There was denser SHG formation in the Resource Support Centre (RSC) (Bommalinganahalli and Rayapura) and MYRADA (Devarahatti) villages due to the better effort by the NGO staff in organising the village community, while such an effort was less visible in the Group for Urban and Rural Development (GUARD) villages (Tumkurlahalli and Marlahalli).

Table 3: Distribution of farmers (\%) by villages and membership in KAWAD initiated SHGs

\begin{tabular}{|l|l|l|l|}
\hline Village & $\begin{array}{l}\text { Nobody is a } \\
\text { member }\end{array}$ & $\begin{array}{l}\text { At least one } \\
\text { household member }\end{array}$ & Total \\
\hline Tumkurlahalli & 21 & 79 & $100(38)$ \\
\hline Marlahalli & 28 & 72 & $100(29)$ \\
\hline Devarahatti & 16 & 84 & $100(38)$ \\
\hline Rayapura & 19 & 81 & $100(36)$ \\
\hline Bommalinganahalli & 15 & 85 & $100(34)$ \\
\hline
\end{tabular}

Note: Figures in parentheses are actual numbers

The denser SHG membership among the sample farm households leads us to expect that a larger proportion of households would have participated in MWSDC meetings, transact walk, decisionmaking on treatment and payment of contribution. The evidence, however, suggests that although 97 percent of the farmers stated that they attended the meeting of the MWSDC to select its representatives, awareness level of their MWSDC representative was moderate (Table 4).

For a crucial variable, decision-making on the treatment in the plot, a significant proportion of decisions (22\%) among the sample farmers was made without their consent. The area under each MWSDC was not more than 500 hectares. This would imply that the number of farmers would also be less. This design feature was to ensure more face-to-face interaction between the farmers

\footnotetext{
${ }^{7}$ We have anecdotal evidence to suggest that there have been cases, wherein certain SHGs have been 'entrepreneurial' in getting loans from KAWAD to the extent of Rs. 200,000 (for a group) and have not made the necessary repayment to KAWAD as per the agreed terms and conditions.
} 
and MWSDC members. This was expected to lead to the provisioning of the collective good as per the theoretical proposition of the Olson that smaller the size better is the provisioning of the collective good. Let us now look at the evidence.

Table 4: Distribution of farmers (\%) by farm categories and ability to identify representatives

\begin{tabular}{|l|l|l|l|l|l|}
\hline \multirow{2}{*}{ Stratum } & \multicolumn{2}{l}{ Village } & \multicolumn{4}{l|}{ Farmers (\%) identifying representatives } \\
\cline { 2 - 6 } & At least one & None & Village & At least one & None \\
\hline Upper small & 58 & 42 & Tumkurlahalli & 79 & 21 \\
\hline Upper medium & 45 & 55 & Marlahalli & 52 & 48 \\
\hline Upper large & 70 & 30 & Devarahatti & 66 & 34 \\
\hline Lower small & 67 & 33 & Rayapura & 47 & 53 \\
\hline Lower medium & 65 & 35 & Bommalinganahalli & 59 & 41 \\
\hline Lower large & 64 & 36 & & & \\
\hline All farmers & $61(107)$ & $39(68)$ & & & \\
\hline
\end{tabular}

Note: Figures in parentheses are actual numbers

The proportion of farmers who were able to identify at least one of the representatives was 61 percent. The awareness was the highest in Tumkurlahalli village (Table 4). The perception of 61 percent of the farmers in Tumkurlahalli was that the first representative was good, although 26 percent of farmers did express that they had no contact with him. The farmers recognised his role in convincing the farmers to undertake the soil and water conservation (SWC) treatment in their land. The first representative also played a decisive role in ensuring collective action among land owners whose lands were located next to each other, so that work could be done in a sequential manner leading to the construction of a diversion drain. This representative, however, could not prevent wealth seeking behaviour. 'Wealth seeking' in the context of this study refers to the process wherein the various actors (farmers, NGO staff, 'new' contractors) compromise on the quantum and quality of SWC treatment, including the payment of contribution and generate wealth through such 'adjustments'. By 'adjustments', we mean the following. For illustration, we use the example of tank-silt application. The farmer states that he requires four tractor loads of tank silt to be applied to his plots. The contribution norm for this activity is 50 percent of the costs. Since the farmer is unwilling to pay such high costs as contribution, he ensures that only two tractor loads of tank silt are deposited in the plot. By indulging in such malpractices, he ensures that he does not have to pay any contribution upfront as the amount 'saved' is shown as contribution and rest of the money is pocketed by the farmer. In some cases, the 'spoils' are shared among the farmer and NGO staff.

The Tumkurlahalli MWSDC, in one of its meetings, had asked the farmers to get their land treated through the contractors, which was a clear violation of the KAWAD guidelines. The guidelines required that the farmer himself/herself undertake the treatment. The majority of the farmers in Marlahalli (52\%) stated that the representative was good and only 10 percent expressed the opinion that the lady was corrupt. However, this perception does not stand the test of the empirical data on contribution as we have documented the 'adjustments' that the lady fixer undertook by co-opting the GUARD NGO staff. The representative in Devarahatti ${ }^{8}$ is the least visible with 47 percent of the farmers having no contact with the representative. The 'corrupt' nature of the representative which we have documented was stated by only 10 percent of the farmers. The perception among 64 percent of the farmers in the RSC-operated villages was that

${ }^{8}$ This is the village where the implementation agency, MYRADA, is involved in implementation. 
the representative played a positive role (Table 5). The evidence from the data on contributions has revealed that although the representatives themselves were not corrupt in Bommalinganahalli and Rayapura villages, they could not prevent the 'adjustments' from taking place.

Table 5: Distribution of farmers (\%) by villages and opinion on MWSDC representative

\begin{tabular}{|l|r|r|r|l|l|l|}
\hline Village & $\begin{array}{l}\text { No } \\
\text { contact }\end{array}$ & Good & Corrupt & $\begin{array}{l}\text { Helps only } \\
\text { those close } \\
\text { to him }\end{array}$ & $\begin{array}{l}\text { Not done } \\
\text { any work }\end{array}$ & Total \\
\hline Tumkurlahalli & 26 & 61 & 3 & 6 & 4 & $100(38)$ \\
\hline Marlahalli & 24 & 52 & 10 & 0 & 14 & $100(29)$ \\
\hline Devarahatti & 47 & 32 & 10 & 0 & 11 & $100(38)$ \\
\hline Rayapura & 31 & 64 & 0 & 0 & 5 & $100(36)$ \\
\hline Bommalinganahalli & 27 & 65 & 3 & 0 & 5 & $100(34)$ \\
\hline
\end{tabular}

Note: Figures in parentheses are actual numbers

In the KAWAD intervention, the MWSDCs crafted were supposed to play an active role in supporting participatory processes of planning and implementation with the active support and facilitation of the NGO staff. There have been compromises in the programme implementation with a collusive behaviour of the farmer-MWSDC member (either the representative or record writer or both) or NGO staff in facilitating 'adjustments' which lead to the poor quality and quantum of the SWC treatment. In the GUARD villages, while in Tumkurlahalli, the first and second representatives were not corrupt, quite a bit of 'adjustments' took place with the MWSDC stating in one of its meetings that the farmers could give the work to contractors to get their work done (so that they could avoid paying the upfront contribution as mandated by the project). Many 'new' contractors emerged in this village. These contractors are referred to as 'new' contractors as these people were ordinary farmers who assessed the wealth seeking opportunities that the project provided and emerged as contractors.

In the other GUARD village of Marlahalli, the first representative (a lady) emerged as the fixer who facilitated collusive behaviour leading to no consent treatments and 'adjustments'. In the RSC village, of Bommalinganahalli, the record writer of the MWSDC was corrupt and undertook 'adjustments' and the farmers were cheated as they were asked to pay more money than it was required as per the norm. Similarly, in Rayapura, the record writer was involved in facilitating 'adjustments'. In Devarahatti, the first representative himself was the 'new' contractor and facilitated the various 'adjustments' that took place. Although the strategy of KAWAD in having smaller MWSDCs was to some extent successful in ensuring visibility and more face-to-face interaction between the farmers and MWSDC members, this did not lead to the provisioning of the collective good. There was a collective 'bad' outcome with wealth-seeking activities being undertaken by a variety of actors (farmers, NGO staff) with the co-option of the MWSDC representatives/record writer.

\section{Decision Making on the Soil and Water Conservation Treatment}

In the KAWAD mode, the decision making on the soil and water conservation treatment in a plot was to be based on the request by the farmer and his agreement to pay the contribution amount (upfront) as per the norm. The farmer was also expected to participate in the transact walk. The evidence, however, reveals that in a significant proportion of cases, either passive forms of decision making took place or consent was taken in $30 \%$ cases or no consent of the farmer (18\%) 
was taken (Table 6). In the former case, the decision was taken by the NGO staff or MWSDC member. Better forms of decision-making such as the farmer requesting treatment took place in 35 percent of the cases. Further, 'joint' decision making with the farmer requesting the NGO staff to come to the plot or NGO staff requesting the farmer to come to the plot took place in 17 percent of the cases.

Table 6: Distribution of farmers (\%) by farm categories and decision-making on the treatment

\begin{tabular}{|l|r|r|r|l|r|}
\hline Stratum & $\begin{array}{l}\text { No } \\
\text { consent }\end{array}$ & $\begin{array}{l}\text { Consent } \\
\text { taken }\end{array}$ & $\begin{array}{l}\text { Farmer } \\
\text { requests }\end{array}$ & $\begin{array}{l}\text { Joint decision making } \\
\text { Staff/WDC member } \\
\text { take farmer to the plot })\end{array}$ & \multicolumn{1}{l|}{ Total } \\
\hline Upper small & 23 & 39 & 23 & 15 & $100(26)$ \\
\hline Upper medium & 21 & 35 & 31 & 13 & $100(29)$ \\
\hline Upper large & 13 & 22 & 30 & 35 & $100(23)$ \\
\hline Lower small & 15 & 30 & 33 & 22 & $100(27)$ \\
\hline Lower medium & 15 & 30 & 50 & 5 & $100(34)$ \\
\hline Lower large & 19 & 28 & 39 & 14 & $100(36)$ \\
\hline All farmers & $18(31)$ & $30(52)$ & $35(62)$ & $17(30)$ & $100(175)$ \\
\hline
\end{tabular}

We now proceed to examine each of the modes of decision-making. In 18 percent of the cases, the decision was made without consent, this was the highest among the upper small stratum $(23 \%)$ followed by upper medium $(21 \%)$. The proportion of no consent cases was relatively high in Marlahalli and Rayapura villages. In Rayapura, the reason was that the staff did not bother to consult the farmers for farm bunds as they had already got some indication that the farmers did not want this treatment work. They were under pressure to get the treatment completed to show physical and financial progress as per the approved estimates. The reason for such high no consent treatments occurring in the GUARD village of Marlahalli was, as explained earlier, due to the lack of NGO's efforts to ensure that consent is taken, and the omnipotent role of the lady fixer who colluded with NGO staff to undertake 'adjustments' and no consent treatments.

In another GUARD village (Tumkurlahalli), no consent treatment was the least as the GUARD NGO's office was located within the village, and, therefore, its staff were easily accessible. In Devarahatti (MYRADA village), no consent treatments occurred as the 'new' contractor (first representative in the MWSDC) undertook the treatments with 'adjustments', without bothering to consult the farmer. An unexpected finding is that although the NGO staff (Resource Support Centre) in Bommalinganahalli were more committed to ensure participatory decision making, no consent treatments occurred in 9 percent of the cases.

The average land owned by the no consent households was 13.78 acres as compared to 9.46 acres for the entire sample of households. Concerning irrigation, while the no consent households owned 3.3 acres of land, it was only 1.8 acres for the entire sample. With respect to awareness of the existence of the MWSDC, while 68 percent of the no consent households were aware, it was only 54 percent for the entire sample. Concerning the awareness of the existence of the Field Officer, the awareness level was marginally lesser among the no consent households, 71 percent as compared to 75 percent among the entire sample of households. The above suggests that better endowment does not necessarily mean that the staff or MWSDC members would prefer to take consent of the farmer.

In 30 percent of the cases, consent was taken. The proportion of the cases was the highest in the 
upper small stratum (39\%), followed by upper medium (35\%) and the upper large stratum (22\%). More passive modes of decision-making took place among small and medium farmers in the upper reach as compared to those in the lower reach. The dominant mode of decision-making in the KAWAD villages was a request by farmers for a particular treatment. In 17 percent of the cases, the decision was 'jointly' (Field Officer/MWSDC members taking the farmer to the plot or the other way around) made, which is being the highest in the upper large stratum and least in the lower large stratum. Farmers made more significant efforts in the upper large stratum, as they wanted the boulders in their plots to be removed, which was the most sought-after SWC treatment in the project. Joint decision-making cases were the highest in Bommalinganahalli (50\%) due to better efforts by the RSC staff.

Table 7: Distribution of farmers (\%) by villages and decision making on the treatment

\begin{tabular}{|l|r|l|l|l|r|}
\hline Village & $\begin{array}{l}\text { No } \\
\text { consent }\end{array}$ & $\begin{array}{l}\text { Consent } \\
\text { taken }\end{array}$ & $\begin{array}{l}\text { Farmer } \\
\text { requests }\end{array}$ & $\begin{array}{l}\text { Joint Decision making } \\
\text { Staff/WDC member } \\
\text { take farmer to the plot })\end{array}$ & \multicolumn{1}{l|}{ Total } \\
\hline Tumkurlahalli & 3 & 29 & 58 & 10 & $100(38)$ \\
\hline Marlahalli & 55 & 24 & 21 & 0 & $100(29)$ \\
\hline Devarahatti & 13 & 34 & 37 & 16 & $100(38)$ \\
\hline Rayapura & 17 & 44 & 33 & 6 & $100(36)$ \\
\hline Bommalinganahalli & 9 & 18 & 24 & 49 & $100(34)$ \\
\hline
\end{tabular}

\section{Participation in the Transact Walk}

The decision-making process in the KAWAD project was based on a demand-driven approach, wherein the farmer could request for a particular soil and conservation treatment and based on an upfront contribution being paid, the farmer could get his/her plot treated. The farmer was also supposed to participate in the transact walk and contribute to the decision-making process for the entire micro-watershed including the treatment plan for his/her plot. The project envisaged that such a method of participatory planning would lead to a more participatory process of arriving at the treatment plan for the micro-watershed. Let us now look at the evidence on participation of farmers in the transact walk.

About 18 percent of the farmers were not aware of the transact walk being conducted with this proportion being the highest among the lower large reach (25\%) (Table 8). The decision-making was based mainly on the farmer requesting a particular SWC treatment (39\%). Forty percent of the farmers were aware but chose not to participate in the transact walk, this proportion is the highest in the lower medium reach (47\%). Fifty percent of the farmers in the lower medium reach chose to put forth a request to the NGO staff. 42 percent of the farmers did attend the transact, the highest proportion of these farmers were from the upper large stratum (48\%) while the least percentage was from the lower large stratum (36\%) (Table 8). The reason is that the need for boulder removal work was comparatively a more acute problem in the upper reaches of the micro watershed than the lower reach. Therefore, farmers in the upper large reach had a better incentive to participate in the transact to ensure good quality of SWC treatment. 
Table 8: Distribution of farmers (\%) by farm categories and participation in the transact walk

\begin{tabular}{|l|r|r|r|r|}
\hline Stratum & \multicolumn{1}{l}{ Not aware } & \multicolumn{1}{c|}{$\begin{array}{c}\text { Aware, did not } \\
\text { participate }\end{array}$} & \multicolumn{1}{c|}{ Participated } & \multicolumn{1}{l|}{ Total } \\
\hline Upper small & 19 & 42 & 39 & $100(26)$ \\
\hline Upper medium & 17 & 38 & 45 & $100(29)$ \\
\hline Upper large & 17 & 35 & 48 & $100(23)$ \\
\hline Lower small & 15 & 37 & 48 & $100(27)$ \\
\hline Lower medium & 12 & 47 & 41 & $100(34)$ \\
\hline Lower large & 25 & 39 & 36 & $100(36)$ \\
\hline Total & $18(31)$ & $40(70)$ & $42(74)$ & $100(175)$ \\
\hline
\end{tabular}

Note: Figures in parentheses are actual numbers

The highest proportion of farmers attending the transact walk was from Bommalinganahalli, followed by Devarahatti village (Table 9). This was due to the better efforts made by the RSC and MYRADA staff to motivate the farmers to participate in the transact walk to ensure greater ownership of the planning process. Marlahalli village has the lowest proportion of farmers participating in the transect walk (3\%), highest proportion of farmers being aware, but not attending the transact walk (59\%) and the highest proportion of farmers being unaware of the transact walk (38\%). In Marlahalli village, the participation in the transact walk was low as nonparticipatory modes of decision-making (no consent treatments) occurred due to lack of effort by the NGO staff and the omnipotent role of the lady fixer, who largely took decisions without consulting the farmer. In Rayapura, the participation in the transact walk was less (31\%) and there were no consent treatment cases with respect to farm bund treatment.

Table 9: Distribution of farmers (\%) by villages and participation in the transact walk

\begin{tabular}{|l|r|r|r|r|}
\hline Village & Not aware & \multicolumn{2}{|l|}{$\begin{array}{l}\text { Aware, did not } \\
\text { participate }\end{array}$} & \multicolumn{2}{l|}{ Participated } & \multicolumn{1}{l|}{ Total } \\
\hline Tumkurlahalli & 10 & 45 & 45 & $100(38)$ \\
\hline Marlahalli & 38 & 59 & 3 & $100(29)$ \\
\hline Devarahatti & 21 & 18 & 61 & $100(38)$ \\
\hline Rayapura & 20 & 49 & 31 & $100(35)$ \\
\hline Bommalinganahalli & 3 & 32 & 65 & $100(34)$ \\
\hline
\end{tabular}

Fifty-eight percent of the farmers did not participate in the transact walk. Of 42 percent of the farmers who participated in the walk, 17 percent spent less than five hours during walk, 10 percent spent between 5-12 hours and 15 percent spent more than one day. Many of those falling in the time span of over 12 hours, had spent 4-5 days (Table 11). In the most active category of participation (more than 12 hours), the highest participation was from the farmers in the upper medium (28\%) and upper large stratum (26\%), mostly to get the boulders removed from their plots. While the small farmers also faced the problem of the boulders in their plot, they did not participate either because of their inability to pay the upfront contribution costs or due to their 'inability' to be tactful in facilitating 'adjustments'.

Table 10: Distribution of farmers (\%) by farm categories and time spent in the transact walk

\begin{tabular}{|c|c|c|c|c|c|}
\hline \multirow[t]{2}{*}{ Stratum } & \multicolumn{5}{|c|}{ Number of hours spent by farmers (\%) in transact walk } \\
\hline & Nil & $<5$ & 5 to 12 & $>12$ & Total \\
\hline Upper small & 62 & 19 & 15 & 4 & $100(26)$ \\
\hline
\end{tabular}

G. Ananda Vadivelu 


\begin{tabular}{|l|r|r|r|r|r|}
\hline Upper medium & 55 & 14 & 3 & 28 & $100(29)$ \\
\hline Upper large & 52 & 13 & 9 & 26 & $100(23)$ \\
\hline Lower small & 52 & 15 & 11 & 22 & $100(27)$ \\
\hline Lower medium & 56 & 18 & 9 & 17 & $100(34)$ \\
\hline Lower large & 64 & 8 & 3 & 25 & $100(36)$ \\
\hline Total & $58(101)$ & $17(30)$ & $10(18)$ & $15(26)$ & $100(175)$ \\
\hline
\end{tabular}

Note: Figures in parentheses are actual numbers

\section{Conclusion}

KAWAD project, in its design, placed considerable emphasis on the formation of communitybased organisations (SHGs, MWSDCs) and a smaller size of the MWSDC. This, however, did not result in their effective participation in the planning and implementation of watershed interventions. The creation of social capital is supposed to facilitate a shared understanding and develop patterns of interaction among individuals who work under a collective identity. It was also expected that the self-interest maximising behaviour of individuals would be restricted, and they would work in the interest of the collectivity (Coleman, 1998, p.104). The present study, however, found that the social capital formation and its manifestation through the Micro Watershed Development Committee (MWSDC) did not facilitate the desired processes. A clear case is in Tumkurahalli village, were the MWSDC itself asked the farmers to get their soil and water conservation treatment through contractors clearly violating the guidelines that the treatment has to be done by the farmer himself. In other villages the contractors were used through the interaction of the farmer and NGO staff with the contractors directly.

While it is theorised that social capital can solve the free rider problem, the evidence from present field study clearly demonstrates that the mode of project implementation through the contractors ensured free riding by the farmers. The farmers were engaged in corrupt practices in collusion with other actors. Another dimension to the free-riding issue is demonstrated with respect to the participation in the transact walk, with $40 \%$ of the farmers aware of the transact walk, but not participating in it. They did not participate despite being aware, because they knew that irrespective of their participation, a decision would be undertaken on the nature of soil and water conservation treatment that would be undertaken on their land and their land would get treated.

The small size of the MWSDC was supposed to ensure more face-to-face interaction between the farmers and MWSDC members. This was expected to lead to the provisioning of the collective good as per the theoretical proposition of the Olson (1965) that smaller the size of the group, better is the provisioning of the collective good. The present study, however, demonstrates that such provisioning could also lead to a bad outcome. The study provides evidence that provisioning by small groups can lead to collusive behaviour. Thus, study contributes to the literature that provides evidence that size is a necessary, but not sufficient condition for provisioning of the collective good in heterogeneous communities.

\section{References}

Aggarwal, M.R. (2000). Possibilities and Limitations to Cooperation in Small Groups: The Case of Group Owned Wells in Southern India, World Development, 28(8): 1481-1497.

Baland, Jean-Marie and Platteau, Jean-Philippe (1996). Halting Degradation of Natural Resources - Is There a Role for Rural Communities? New Delhi: Oxford University Press. 
Barnes, C. and Van Laerhoven, F. (2013). Helping to self-help? External interventions to stimulate local collective action in Joint Forest Management, Maharashtra, India, International Forestry Review, 15(1): 1-17.

Coleman, J. (1988). Social capital in the creation of human capital, American Journal of Sociology, 94(Suppl.): S95-S120.

Cornwall, Andrea (2008). Unpacking 'Participation': models, meanings and practices", Community Development Journal, 43(3): 269-283.

D'Silva, E. and Pai, S. (2003). Social Capital and Collective Action, Development Outcomes in Forest Protection and Watershed Development, Economic and Political Weekly, 38(14): 1404-1415.

Dayton-Johnson, J. and Bardhan, P. (2002). Inequality and Conservation on the Local Commons: A Theoretical Exercise, Economic Journal, 112(481): 577-602.

Farrington, J. and Lobo, C. (1997). Scaling Up Participatory Watershed Development in India: Lessons from the Indo German Watershed Development Programme, Natural Resource Perspectives, No.17, February.

Fernandez, A. (1994). The MYRADA Experience: The Interventions of a Voluntary Agency in the Emergence and Growth of People's Institutions for Sustained and Equitable Management of Microwatersheds, Bangalore: MYRADA.

Keohae, O. and Ostrom, E. (1995) Local Commons and Global Interdependence, London: Sage Publications. DOI: http://dx.doi.org/10.4135/9781446222010.

Mansuri, G. and Rao, V. (2013). Localizing Development: Does Participation Work? Policy Research Report. Washington, DC: World Bank. Available online at https://openknowledge.worldbank.org/handle/10986/11859, accessed on $16^{\text {th }}$ January 2018.

Olson, M. (1965). The Logic of Collective Action: Public Goods and the Theory of Groups, Harvard: Harvard University Press.

Ostrom, Elinor (1990). Governing the Commons: The Evolution of Institutions for Collective Action, New York: Cambridge University Press.

Singh, K. and Ballabh, V. (1994). Role of Leadership in Cooperative Management of Natural Common Pool Resource: A Collective Good Theoretic Perspective. Working Paper Series, No. 50. Anand (India): Institute of Rural Management Anand (IRMA).

Vedeld, T. (2000). Village Politics: Heterogeneity, Leadership and Collective Action, Journal of Development Studies, 36(5): 105-134.

Wade, R. (1988). Village Republics, Economic Conditions for Collective Action in South India, Cambridge: Cambridge University Press. 